\begin{tabular}{|l|l|}
\hline Asian Journal of Pharmaceutical Research \\
and Development \\
(An International Peer-Reviewed Journal of Pharmaceutical Research and Development) \\
@ 2013-18, publisher and licensee AJPRD, This is an Open Access article which permits unrestricted \\
non-commercial use, provided the original work is properly cited
\end{tabular}

\title{
PHARMACOLOGY EFFECT OF CARDIOVASCULAR DRUGS ON THE LEVEL OF THYROID HORMONES AND VITAMIN-D.
}

\author{
Painuly Neelam* ${ }^{*}$, Sharma Amit
}

Department of Pharmacy, Manav Bharti University, Solan, Himachal Pradesh India

\begin{abstract}
:-
Cardiovascular system is an important system of body. This consists the heart and blood vessels. Any kind of heart disease is dangerous. Thyroid hormone is one of the leading hormones which is involving in the cardiovascular mechanism. Any disturbance in the balance of hormone can cause serious problems which may be dangerous to cardiovascular system. So it balance should be maintained properly. Various treatment related to this are found but they may cause various alteration in the production of thyroid hormone. So in order to give proper treatment to patient all the aspects should be checked and observed properly considering the health of patient. Amlodipine, Propranolol, Captopril, Amiodarone are some of the medicines used in the treatment of these diseases. Knowledge of drug should be proper so that any risk of thyroid abnormalities can be minimized and diagnosed in proper time.
\end{abstract}

Key words: Arrhythmia, cardiovascular, vitamin D, Amlodipine, Propranolol, Captopril, Amiodarone

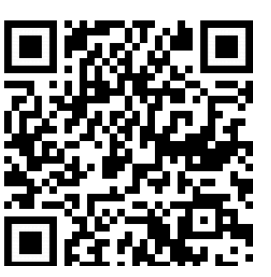
Cite this article as:

Painuly Neelam, Pharmacology Effect of Cardiovascular Drugs on the Level of Thyroid Hormones and Vitamin-D, Asian Journal of Pharmaceutical research and Development.2018; 6 (4): 30-34

\section{DOI: http://dx.doi.org/10.22270/ajprd.v6.i4.382}

\section{*Address for Correspondence}

Neelam Painuly, Asst. Professor ,Department of Pharmacy, Manav Bharti University, Solan, Himachal Pradesh India.

\section{INTRODUCTION}

$\mathrm{T}$ he cardiovascular system consists of heart and blood vessels. It is mainly a transport system. Blood is the medium through which these substance are transported ${ }^{1}$. Cardiovascular disease is the leading cause of illness and death worldwide, approximately 946,000 deaths were attributable to cardiovascular disease. Clinical trials have provided compelling evidence that coronary heart disease is largely preventable. Heart diseases are grouped into three major disorders: cardiac failure, ischemia (with angina) and cardiac arrhythmia ${ }^{2}$. When people are diagnosed with heart disease, they may be treated in several different ways. Smoking-will be the first changes they will have to make ${ }^{3}$. Whereas next will be the drug they are taking. Cardiovascular disease (CVDs) is a disease which affects the major part of heart and the blood vessels and they include: coronary heart disease, cerebrovascular disease, peripheral arterial disease, rheumatic heart disease, congenital heart disease, deep vein thrombosis and pulmonary embolism etc. By 2030, almost 25 million people will die from CVDs, mainly from heart disease and stroke. These are projected to remain the single leading cause of death, $51 \%$ of deaths due to strokes and $45 \%$ of deaths due to coronary heart disease $^{4}$. About 1000 prescriptions were selected from randomly viewed 1200 prescriptions of National Heart Foundation \& Dhaka Medical College Hospital outdoor. This Survey was carried out at the outdoor of National Heart Foundation \& Dhaka Medical College Hospital, Dhaka, Bangladesh from Jan'12 to August'12. This data may be guidelines for optimizing rational use of cardiovascular drugs and also a new statistical approach for effective cardiovascular disease management in Bangladesh ${ }^{5}$. The thyroid Gland is a small butterfly shaped endocrine gland, located in the lower part of the neck. The main hormones released by the thyroid are T3 and T4 which deliver energy to cells of the body ${ }^{6}$.Thyroid hormone is very much important for body's metabolism regulation, it also affect heart rate, temperature of the body and regulate its utilization of 
energy from the food. Thyroid associated disorders may be classified into two major parts/ categories: Hyperthyroidism \& Hypothyroidism. Hypothyroidism is caused by severe iron deficiency which leads to decrease in production of thyroid hormone also alter thyroid gland function. ${ }^{7}$ This can also be classified into: Primary hypothyroidism and Secondary hypothyroidism. In primary hypothyroidism the body stimulate thyroid properly but isn't able to secrete enough thyroid hormone while in secondary hypothyroidism pituitary gland is not able to regulate thyroid so that there is improper production of thyroid hormone.In adult myocardium thyroid hormone is conceded as a powerful regulator of vasculature. Therefore the low free T3 state can decrease/ inhibit neovascularization in myocardium. According to WHO, iodine deficiency can cause severe problem like mental retardation, abortion, congenital abnormalities ${ }^{8}$.

\section{REVIEW OF LITERATURE:-}

The cardiovascular system consists of heart and blood vessels. It which blood is act as a transporter and carry gases, nutrients, and excretory products throughout the body. The heart is situated in the thorax in between the lungs and the middle portion of chest. The heart is divided in four chambers. The upper portion of heart is called as atrium/ atria, and the lower portion of heart is called ventricles. Upper right chamber is called as right atrium. The opening between the right atrium and right ventricles is known as tricuspid valve. Whereas the opening between the left atrium and left ventricles is known as bicuspid valve receives superior vena cava and inferior vena cava. They carry venous blood to heart. From the right ventricle, arises the pulmonary artery. It carries venous blood to lungs for oxygenation. The left atrium receives four pulmonary veins. They carry oxygenated blood to heart. Heart is supplied by sympathetic and vagus nerves ${ }^{9}$. The heart pump blood into arteries. The arteries divide and subdivide and finally end in capillaries. The capillaries later unite to form veins. The veins return blood to the heart. Cardiac failure, Stenosis of valves, Incompetences of valves, Ischemic heart disease, Angina pectoris, Myocardial infarction, Cardiac arrhythmia, Arteriosclerosis, Atherosclerosis, Thrombus, Hypertension, Hypotension.

Table No. 1:- Therapeutic drug categories ${ }^{10}$

\begin{tabular}{|l|l|}
\hline \multicolumn{1}{|c|}{ DISEASE } & \multicolumn{1}{c|}{ CLASSIFICATION OF DRUGS } \\
\hline Drugs to treat angina & Beta blockers, calcium channel blockers, nitrates \\
\hline Drugs to treat blood clot disorders & Anticoagulants \\
\hline Drugs to treat heart failure & ACE inhibitors, combination drugs, diuretics, digitalis drugs. \\
\hline $\begin{array}{l}\text { Drugs to treat heart rhythm } \\
\text { disorders(arrhythmias) }\end{array}$ & $\begin{array}{l}\text { Antiarrhythmic drugs, anti- coagulant, beta blockers, calcium channel } \\
\text { blockers, digitalis drugs. }\end{array}$ \\
\hline $\begin{array}{l}\text { Drug to treat high blood } \\
\text { pressure(hypertension) }\end{array}$ & $\begin{array}{l}\text { ACE inhibitors, alpha blockers, alpha and beta blockers, beta blockers, } \\
\text { calcium channel blockers, centrally acting drugs, combination drugs, } \\
\text { diuretics, peripheral adrenergic antagonists, vasodilators }\end{array}$ \\
\hline Drugs to treat high cholesterol & Cholesterol-lowering agents. \\
\hline Post-heart attack drugs & Anticoagulants, thrombolytic, and antiplatelet, beta blockers \\
\hline Post- heart valve replacement drugs. & Anticoagulants \\
\hline
\end{tabular}

The thyroid hormones, triiodothyronine $\left(\mathrm{T}_{3}\right)$ and its prohormone, thyroxin $\left(\mathrm{T}_{4}\right)$, are tyrosine-based hormones produced by the thyroid gland that are primarily responsible for regulation of metabolism. Any lesser amount of iodine leads to lesser amount of T3 and T4 which in turn enlarge the tissue of thyroid and result in goiter. Chief from of thyroid in our body is T4and this form act on each cell of body it help in growth development metabolism of the body. It also regulate protein synthesis. It also help in differentiate of various cell in our body. It also regulate body heat ${ }^{11}$.

\section{MECHANISM OF ACTION}

Thyroid hormones many function through nuclear receptors and the nucleus. This receptor bind DNA molecule along with co receptor molecule called as (TREs) genes ${ }^{12}$.

\section{VITAMIN-D}

The term 'vitamin D' generally refers to two very similar molecules. Vit. D3, called as cholecalciferol, formed by cells of skin in reaction with UV rays. Vitamin D2, or ergocalciferol, occurs naturally in some mushrooms and yeast. The major natural source of vitamin D is exposure of the skin to ultraviolet B wavelengths in sunlight. However, there are risks of skin cancer associated with extended exposure to sunlight. The amt. of vit. D absorbed in the skin cell with less darker skin in overweight people. Fish like Oily trout have the huge amt. of vit. D3. Vit. D2 present in some mushrooms. These are 2kinds of vit.D supplements: vit. D2 and vit. D3. Vit. D concentration given by calculating of $25 \mathrm{D}$ in the blood ${ }^{13}$.

\section{Research Hypothesis}

Pharmacological treatment of cardiovascular disorders can lead to alterations in endocrine function through effects on glucose homeostasis, thyroid and parathyroid hormones, adrenal steroid metabolism and 
reproductive/pituitary physiology ${ }^{14}$. Thyroid hormone exerts both genomic and non genomic effects on cardiac myocytes. The genomic effects of thyroid hormone are mediated by the transcriptional activation or repression of specific target genes. thyroid hormone that accounts for the vast majority of thyroid effects including stimulation of tissue thermogenesis , alterations in the expression of various cellular proteins and action on the heart and vascular smooth muscle cells ${ }^{15-16}$. Low level of vitamin $-\mathrm{D}$ causes decrease absorption of calcium triggers Cardiac Complications.

Flow Chart Showing Research Hypothesis

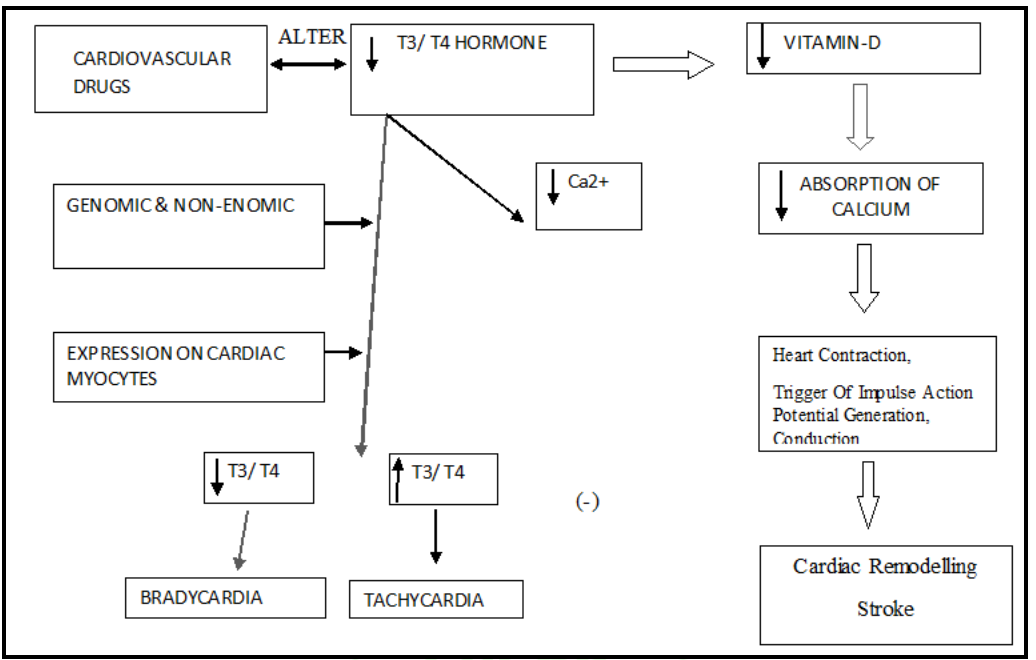

\section{Experimental Protocol:-}

Selection of the patient, Study of patient detail, Inclusion criteria, Exclusion criteria, Study of medication detail, Laboratory analysis.

100 patient of uncomplicated cardiac disorders with age more than 40 were selected. Patient detail must be studied with both inclusion and exclusion criteria. In inclusion criteria both male and female patients with cardiac disorders will be selected above 40 years of age. In exclusion criteria patient with associated diseases will exclude from the study. All the patients randomly selected and divided into groups with 20 patient in each

\section{Conceptual Framework}

group. Receiving different medication. After words T3/T4/Vit. D will be measured in all the patients and levels will be compered with each other as well as baseline population. Sample size will selected by using formula.

Where: $\mathrm{n}=$ Sample size

$$
\mathrm{L}^{2}(\mathrm{~N}-1)+\mathrm{z}^{2} \mathrm{Pq}
$$

$\mathrm{P}=$ Prevalence rate

$\mathrm{q}=100-\mathrm{P}$

$1=$ Allow error

$\mathrm{z}=$ Standard normal distribution

$\mathrm{N}=$ total study population

Health screening of volunteer participants by using survey questionnaire will be done to determine the healthy status of participants .

Patient of Cardiac disorders, associated with other complication will be excluded Screening of patient



Randomly dividing the patient according to cardio vascular drugs , they are prescribed Collection of blood samples

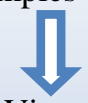

Analyzing the level of $\mathrm{T} 3, \mathrm{~T} 4 \&$ Vitamin-D in blood of patient receiving different cardio vascular drugs

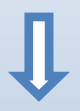

Comparative evaluation of cardio vascular drugs having least effect in T3,T4 levels

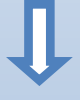

Standardization of safer cardio vascular drugs for uncomplicated cardiac 
Outcome of the study. The outcome of this study could be safer prescription for uncomplicated cardiac disorders with no or minimal cardiovascular complication.

\section{RESULTS:}

Effect of different prescribed drugs on thyroid profile (T4, T3 and TSH level) in cardiac patients:

\section{Reference values:}

Serum T4 - 10.0-28.2pm/L

Serum T3- 4.26-8.10pm/L

Serum TSH $-0.5-5 \mathrm{mU} / \mathrm{ml}$.

Table: 2. Effect of different prescribed drugs on thyroid profile (T4, T3 and TSH level) in cardiac patients:

\begin{tabular}{|l|l|l|l|l|l|}
\hline $\begin{array}{l}\text { Groups } \\
(\mathbf{n}=\mathbf{2 5})\end{array}$ & \multirow{2}{*}{ Drugs } & \multirow{2}{*}{ Dose } & \multicolumn{3}{|l|}{ Parameters } \\
\cline { 4 - 6 } & & $\mathbf{T 4}(\mathbf{p m} / \mathbf{L})$ & $\mathbf{T 3}(\mathbf{p m} / \mathbf{L})$ & TSH $(\mathbf{m I U} / \mathbf{L})$ \\
\hline Group-1 & Amlodipine & $10 \mathrm{mg}$ & $21.4 \pm 1.4$ & $7.13 \pm 0.7$ & $4.1 \pm 0.4$ \\
\hline Group-2 & Amiodarone & $200 \mathrm{mg}$ & $37.3 \pm 2.8^{\mathbf{a}}$ & $11.5 \pm 1.1^{\mathbf{a}}$ & $8.24 \pm 1.3^{\mathbf{a}}$ \\
\hline Group-3 & Propranolol & $160 \mathrm{mg}$ & $32.2 \pm 2.5^{\mathbf{a}}$ & $6.1 \pm 1.4$ & $7.1 \pm 0.7^{\mathbf{a}}$ \\
\hline Group-4 & Captopril & $25 \mathrm{mg}$ & $22.6 \pm 2.2$ & $6.8 \pm 1.1$ & $3.20 \pm 0.6$ \\
\hline
\end{tabular}

Values are expressed as mean SEM, $\mathrm{n}=25$ in each group. Data was analyzed by one-way ANOVA. $\mathrm{a}=\mathrm{P}<0.05$ significant difference from reference values. Doses are mention in $\mathrm{mg}$.

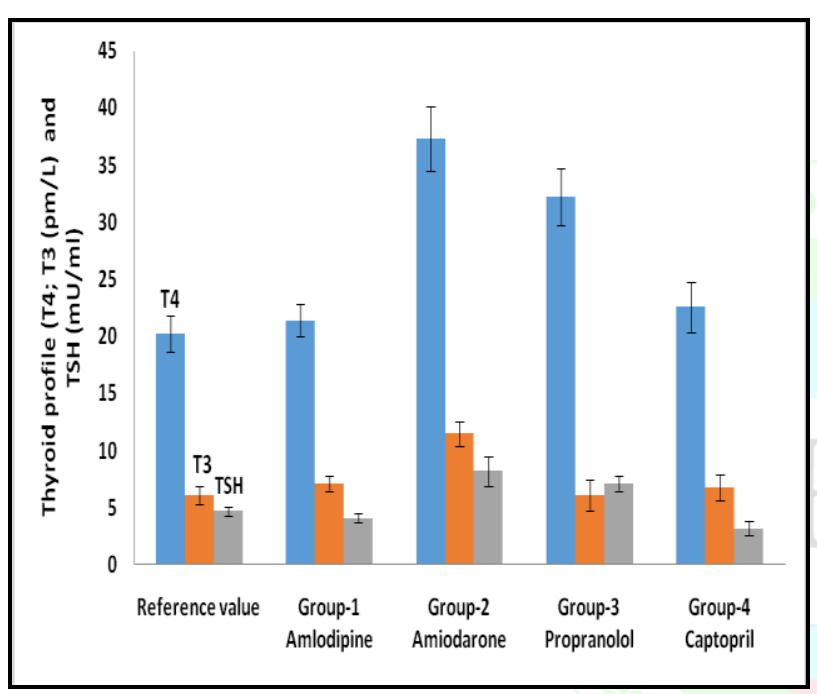

Fig 1: Effect of different prescribed drugs on thyroid profile (T4, T3 and TSH level) in cardiac patients

Values are expressed as mean SEM, $\mathrm{n}=25$ in each group. Data was analyzed by one-way ANOVA. $\mathrm{a}=\mathrm{P}<0.05$ significant difference from reference values. Doses are mention in $\mathrm{mg}$.

Effect of different prescribed drugs on Vitamin D3 (1, 25dihydroxyvitamin $\mathrm{D}$; calcitriol) in cardiac patients:

\section{Reference values:}

Serum Vitamin D3; 20-100 ng/mL

Table: 3. Effect of different prescribed drugs on Vitamin D3 (1, 25-dihydroxyvitamin D; calcitriol) in cardiac patients:

\begin{tabular}{|l|l|l|l|}
\hline $\begin{array}{l}\text { Groups } \\
\text { (n=25) }\end{array}$ & Drugs & Dose & $\begin{array}{l}\text { Parameters } \\
(\mathrm{ng} / \mathrm{mL})\end{array}$ \\
\hline Group-1 & Amlodipine & $10 \mathrm{mg}$ & $35.5 \pm 2.4$ \\
\hline Group-2 & Amiodarone & $200 \mathrm{mg}$ & $40.4 \pm 3.2$ \\
\hline Group-3 & Propranolol & $160 \mathrm{mg}$ & $28.7 \pm 2.6$ \\
\hline Group-4 & Captopril & $25 \mathrm{mg}$ & $25.8 \pm 1.9$ \\
\hline
\end{tabular}

Values are expressed as mean SEM, $\mathrm{n}=25$ in each group. Data was analyzed by one-way ANOVA. Doses are mention in $\mathrm{mg}$.

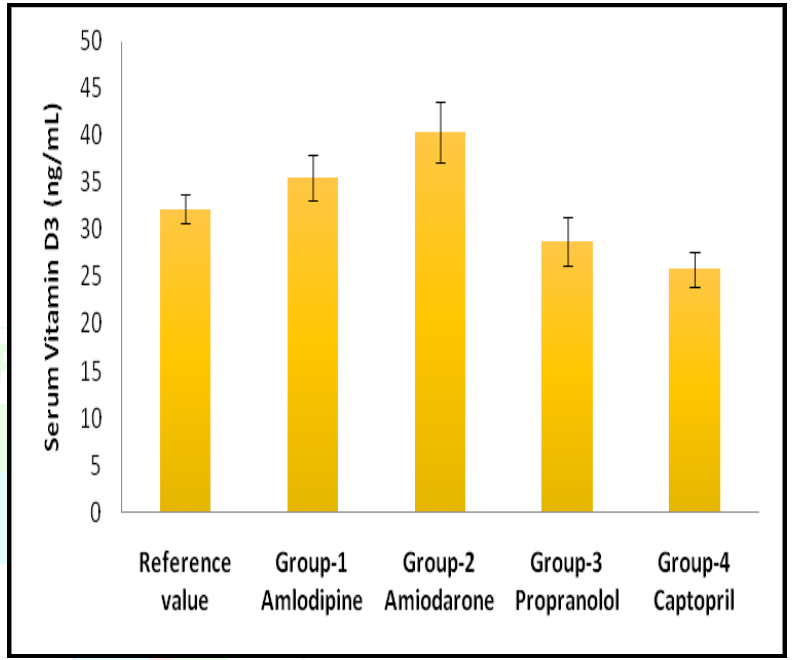

Fig 2: Effect of different prescribed drugs on Vitamin D3 (1, 25-dihydroxyvitamin D; calcitriol) in cardiac patients:

Values are expressed as mean SEM, $n=25$ in each group. Data was analyzed by one-way ANOVA. Doses are mention in $\mathrm{mg}$.

\section{DISCUSSION:-}

In clinic practice testing of thyroid along with its function are becoming common. It is widely observed that some drugs can alter thyroid hormone and cause laboratory test without thyroid disease whereas various other drugs affect thyroid function directly or indirectly and also produce manifest disease. Awareness regarding thyroid disease is increasing and abnormalities related to it are also studied. So patient care should be done properly as there are possible effects of these drugs both on result of thyroid function and effectiveness of treatment and considered decision should be made for the sake of patient. Many drugs produce changes in thyroid hormone and at the same time various problem related are also observed. Large number of compounds are known which may affect thyroid function and may cause thyroid homeostasis. They may also cause change in serum concentration of thyroid hormone by acting at the level of binding protein. Amiodarone effect on the thyroid gland and thyroid hormone metabolism are unique. Propranolol a beta blockers cause decrease in $\mathrm{T} 3$ concentration.

\section{CONCLUSION:-}

The present study conclude that there is no medicine for cardiovascular problem as observed. As cardiovascular medicine alter thyroid level which may be a serious 
complication for the patient. Therefore thyroid testing is becoming part of routine checkup. So the effect of drugs use for thyroid should always considered decisions regarding patient care. These drugs can affect body and cause changing in thyroid hormone balance and can also

\section{REFERENCE:-}

1. George J, Joshi SR, Drugs and Thyroid, Department of Endocrinology, Seth G.S. Medical collage and Kem hospital, Mumbai. 2007; 55: 215-223.

2. Vorperian VR, Havighurst TC, Miller S, January CT. Adverse effects of low dose amiodarone; a meta-analysis.J Am coll cardiol. 30: 791-8, 1997.

3. Murchison LE, How J, Bewsher PD. Comparison of propranolol and metoprolol in the management of Hyperthyroidism. Br J clin pharmacol. 1979; 8: 581-87.

4. Kristensen BO, Weeke J. Propranolol-induced increments in total and free serum thyroxine in patient with essential hypertension. Clin Pharmacol Ther. 1977; 22: 864-7.

5. Sharma A, Arora P, anti-cancer activity of Cedrus depdara in 1,2dimethyl hydrazine $(\mathrm{DMH})$ induced anti-cancer model in rats. Asian Journal of Pharmaceutical Research and Development. 2018; 6(2): 70-74

6. Meier CA, Burger AC. Effects of drugs and other substances on thyroid hormone synthesis and metabolism. In Braverman LE, Utiger RD ed. Werner and IngbarÊs the thyroid: a fundamental and clinical text. Lippincott Williams and Wilkins. 2005; 22-46.

7. Basaria S, Cooper DS. Amiodarone and the thyroid. The American J Medicine. 2005; 118: 706-14.

8. Zittermann A, Schleithoff SS, Koerfer R. Putting cardiovascular disease and vitamin D insufficiency into perspective. Br J Nutr. 2005; 94: 483-92. produce panic result. Knowledge about the medicines that increase the risk of thyroid abnormalities. Would help in monitoring that patient high risk and would lead to early diagnosis and treatment.

9. Aggarwal N, Reis JP, Michos ED. Vitamin D deficiency and its implications on cardiovascular disease. Curr Cardio Risk Rep. 2010; 4: 68-7.

10. McGreevy C, and Williams D, New Insights about Vitamin D and Cardiovascular Disease, Ann Intern Med.2011; 155:820-826.

11. Zhou C, Assem M, Tay JC, Watkins PB, Blumberg B, Schuetz EG, et al. Steroid and xenobiotic receptor and vitamin $\mathrm{D}$ receptor crosstalk mediates CYP24 expression and drug- induced osteomalacia. J Clin Invest. 2006; 16: 1703-12.

12. Van Den Bout-Van Den Beukel CJ, Fievez L, Michels M, Sweep FC, Hermus AR, Bosch ME, et al. Vitamin D deficiency among HIV type 1-infected individuals in the Netherlands: effects of antiretroviral therapy. AIDS Res Hum Retroviruses. 2008; 24:137582

13. Holick MF. Vitamin D deficiency. New England Journal of Medicine. 2007; 357:266-281.

14. Pierrot-Deseilligny C. Clinical implications of a possible role of vitamin D in multiple sclerosis. Journal of Neurology. 2009; 256:1468-1479.

15. National Institute for Health and Clinical Experience. Antenatal care: routine care for the health pregnant woman. 2008; 62 .

16. Sharma A, Arora Pankaj, Anti fertility activity of hydro alcoholic extract of Trillium Govanianum in ethinyl estradiol induced antifertility model in rats. Asian Journal of Pharmaceutical Research and Development. 2018; 6 (2): 62-69. 